\title{
Narrativas transmedia como estrategia para la comprensión lectora
}

\section{Transmedia narratives as a strategy for reading comprehension}

\author{
Angélica María Sánchez-Morocho \\ angelica.sanchez@psg.ucacue.edu.ec \\ Universidad Católica de Cuenca, Azogues \\ Ecuador \\ https://orcid.org/0000-0003-1143-9417 \\ Darwin Gabriel García-Herrera \\ dggarciah@ucacue.edu.ec \\ Universidad Católica de Cuenca, Azogues \\ Ecuador \\ https://orcid.org/0000-0001-6813-8100 \\ Nancy Marcela Cárdenas-Cordero \\ ncardenasc@ucacue.edu.ec \\ Universidad Católica de Cuenca, Azogues \\ Ecuador \\ https://orcid.org/0000-0002-6250-6504 \\ Juan Carlos Erazo-Álvarez \\ jcerazo@ucacue.edu.ec \\ Universidad Católica de Cuenca, Cuenca \\ Ecuador \\ https://orcid.org/0000-0001-6480-2270
}

Recibido: 26 de abril de 2020 Revisado: 31 de mayo de 2020 Aprobado: 16 de junio de 2020

Publicado: 30 de junio de 2020 


\title{
RESUMEN
}

La investigación tiene la finalidad de implementar estrategias basadas en la narrativa transmedia para optimizar la visión leyente en los niños, esto se debe a los problemas que año tras año se viene arrastrando afectando en el transcurso de ilustración directamente. El análisis fue de tipo no experimental descriptiva. La población estuvo integrada por 131 docentes de primaria del distrito 01D03, con un muestreo de 81 docentes. Para la recaudación de datos se recurrió a la encuesta. Los resultados mostraron que es necesario el implementar las estrategias basadas en la narrativa transmedia para un mejor aprendizaje escolar, por ello los estudiantes se sienten atraídos por la tecnología para mostrar interés en los aprendizajes logrando prioridad en la lectura, ya que hoy en día nos encontramos en la ola digital facilitando el leer y el crear historietas desde diferentes dispositivos.

Descriptores: Biblioteca digital; experimento educacional; promoción de la lectura; orientación para la lectura. (Palabras tomadas del Tesauro UNESCO).

\begin{abstract}
The research aims to implement strategies based on the transmedia narrative to optimize reading vision in children, this is due to the problems that year after year are dragging affecting the course of illustration directly. The analysis was descriptive non-experimental. The population consisted of 131 primary teachers from district 01D03, with a sample of 81 teachers. For data collection, the survey was used. The results showed that it is necessary to implement the strategies based on the transmedia narrative for better school learning, therefore students are attracted to technology to show interest in learning, achieving priority in reading, since today we are in the digital wave making it easy to read and create comics from different devices.
\end{abstract}

Descriptors: Digital libraries; educational experiments; reading promotion; reading guidance. (Words taken from the UNESCO Thesaurus). 


\section{INTRODUCCIÓN}

El desarrollo del lenguaje oral y visual se encuentran básicamente relacionados con los aprendizajes de la educación, siendo de gran importancia el determinar el adecuado proceso de ilustración sobre la lectura (Rugerio \& Guevara, 2015) recalcan la importancia de impulsar las prácticas lectoras enriqueciéndolas mediante estrategias innovadoras como lo es la narrativa transmedia como motivación para la lectura. A su vez se tiene en cuenta el alcanzar la lectura como un hábito siendo un proceso que se ve influenciado de la manera en la que es estudiado. (Molas Castells \& Rodríguez Llera, 2017) Afirman que el interés por la lectura va ligado a las estrategias implementadas por los docentes teniendo en cuenta en estas el contexto, tiempo de dedicación, intereses de los estudiantes, entre otras cosas.

Así mismo se da paso al uso de la tecnología, sobresaliendo entre ellas la narrativa transmedia que tiene como propósito fortalecer la comprensión lectora estrategia de complemento despertando los estímulos audiovisuales y digitales encajan perfectamente como instrumentos para el fortalecimiento de la lectura al mismo tiempo, permite fortalecer la formación lectora, bases fundamentales para posteriores aprendizajes. Las Narrativa Transmedia, como historia se desarrollan a través de múltiples plataformas y formatos, son una estrategia, que nos permite el desarrollo intelectual. (Amador Baquiro, 2018) describe la narrativa transmedia como una manera de contar historias a través de múltiples medios, plataformas y formatos. La reproducción de nuevas tecnologías en la actualidad hace muy vigente este estilo de contar historias que se demuestra las hondas ataduras y similitudes entre las narrativas recurrentes legendarias y las narrativas que han germinado al amparo de la revolución digital, para ello, se describe algunos mitos y leyendas en la era digital.

Desde un punto de vista (Amador Baquiro, 2018) manifiesta que Universidad de Barcelona en España se toma en cuenta la intención de introducir la tecnología como una herramienta para explorar la integración de prácticas la narrativa transmedia es una herramienta facilitadora para trabajar competencias que habitualmente no tienen lugar 
dentro del aula formal o bien se trabajan de forma aislada pero que paradójicamente son ineludibles para el progreso de los escolares en la sociedad digital.

Según diversas búsquedas realizadas, el (Ministerio-Educación, 2014) distribuyo gratuitamente textos, con el ánimo de fomentar la lectura, pero es lamentable que el problema siga sumergido, por lo que perturba a un gran número de niños. Por lo que es obligatorio hacer conciencia de lo importante que es tener el hábito lector, dicho así la lectura es la base para los posteriores aprendizajes necesarios en la vida integra del niño y que avancen con mínimos errores en el ámbito escolar de una manera creciente se vaya involucrando con las nuevas tecnologías para tener éxito.

Un estudio realizado en la Universidad Central del Ecuador (Zapata Villa, 2019) fomenta que la narrativa transmedia exige una actitud positiva, que integre y produzca la creación de nuevos contenidos, práctica estrechamente vinculada a la cultura participativa propia de la colectividad de la exploración. Además, es preciso tratar de mejorar la comprensión lectora con la implementación de estrategias basadas en la tecnología como aplicaciones, vídeo juegos, audios, historietas, ya que los docentes deben seguir actualizándose, utilizar estrategias nuevas.

Como objetivo es diseñar estrategias basadas en la narrativa transmedia para la provocar el conocimiento lector en educandos de primaria y proponer su forma de utilización en el aula de clase. Según él (Instituto-Nacional-Censos, 2019) informa que la lectura es decadente por lo tanto el país no es lector, dado así no resulta prioridad, concordando con los esquemas correspondientes, el $52 \%$ de la población leen en una semana de una a dos horas y lo mínimo un libro en un año. Las cantidades arrojan que el $57 \%$ de los ecuatorianos discurren que la lectura es fastidiosa y fatigoso, el $32 \%$ no se ilustra por deterioro de tiempo. Ambato y Guayas son las urbes más lectoras, con $77 \%$, continuas de El Oro con $76 \%$ y La Capital del Ecuador con el 70\%.

Los jóvenes e impúberes son la muchedumbre sobresaliente en leer, esto se debe a que tienen que cumplir obligaciones académicas no más por placer, con la implementación de estrategias basadas en las narrativas transmedia se busca cambiar esta realidad y posicionar a la lectura como prioridad y de disfrute. Domínguez y Correa (2016) 
Angélica María Sánchez Morocho; Darwin Gabriel García-Herrera; Nancy Marcela Cárdenas-Cordero; Juan Carlos Erazo-Álvarez

consideran que leer prematuramente fortifica esta costumbre lectora, incrementa su cabida de información, ayudando a la expresión y desarrollando la creatividad. Esta práctica se construye desde el vientre de la madre ya sea por diferentes medios como los arrullos, el canto medio por el cual el niño comienza asociar la palabra desarrollando la seguridad y el afecto hacia los padres, contagiando de los hábitos útiles en la vida.

Por finalizar los educandos poseen la sensatez de la lectura, le ayuda al enriquecimiento cognitivo, fortalecimiento de la creatividad e imaginación ampliando sus conocimientos y de complementación las tecnologías, pese a ello los docentes de primaria carecen del manejo de las tecnologías por lo que no usan estrategias para incentivar a la comprensión lectora, la ausencia de estrategias causa un retraso en la educación.

\section{Referencial teórico}

La educación está vinculada directamente con la lectura, llegando a ser una prioridad de manera que se establece como uno de los desafíos más difíciles para los docentes, dentro de los propósitos que se tiene es el formar lectores mediante procesos ,centrándose en una competencia para robustecer el conocimiento de interpretación, con el fin a cumplir la necesidad de los estudiantes tomando en cuenta que cada estudiante aprende de diferente forma y tiempo, por lo que indispensable implementar estrategias vinculadas a la tecnología que da un cambio oportuno y sobresaliente a la vez.

Es necesario la comprensión de la lectura porque es evidente, entretenido y de gran interés para los estudiantes, haciendo hincapié la óptima lectura y reflexión de esta, es el mejor medio de aprendizaje y desarrollo del ser humano en aspectos discursivos psicológicos, afectivos y reflexivos, por lo que se diseña diversas estrategias basadas en las narrativa transmedia como herramientas educativas, ampliando espacios de interacción y formación con los estudiantes.

Según (Raúl Fraguela, Pose Porto, \& Lara , 2016) que las características de las estrategias nuevas se diferencian de las tradicionales por sus diferentes particularidades, por lo que en este contexto surge un interés nuevo por la narrativa transmedia 
especialmente con su relación con medios audiovisuales, enriqueciendo la capacidad intelectual por medio de la tecnología.

Es evidentemente que existe un gran problema en las aulas de clases por la forma en que son llevados los procesos de enseñanza de la lectura, en donde se identifica un tipo de apatía y desinterés en los estudiantes frente al tema y con gran preferencia hacia la tecnología lo que surge la necesidad de vincular las narrativas transmedia y hacerles partícipes, de manera que dejen de tener una mirada negativa en el aula. Según (Ministerio-Educación, 2014), diseña, ejecuta bosquejos y proyectos tecnológicos por medio del Sistema Integral de Tecnologías para la Escuela y la Comunidad (SíTEC), para optimizar el estudio digital en el país, pese a ello los docentes no cumplen las directrices con la enseñanza propuesta, siendo que los docentes no se encuentran debidamente actualizados, hecho por el cual la educación no avanza significativamente.

\section{Antecedentes}

A lo largo de la historia la lectura se torna en un inconveniente debido a que los lectores no generan ningún tipo de interés, debido a la falta de textos, recursos, estrategias haciendo que éstos les fueran extraños y que no significaran nada para ellos en su vida y en su educación. Según (López López \& Martínez Viteri, 2019), habla de iniciar la animación a la lectura en España en los años 80 manifiesta que era una época formal, la cual la gente se preparaba aquellos fueron los más resaltados ilustres, dentro de sus casas existían estanterías gigantes con libros era una costumbre que caminada de familia en familia hasta llegar a la escuela. A mediados del siglo se realizan encuestas para evidenciar la alfabetización de la comunidad puesto a ello no resulto lo que se proponían, a los jóvenes no les interesaba leer y los niños preferían jugar lo que se transformó en un reto para animar a la lectura. Se indica que una manera de animar a la lectura es dejando actividades rígidas y optar por prácticas de diferentes técnicas desarrollando la creatividad.

En América latina coincide con España, han surgido proyectos a favor de la lectura como una actividad pionera, donde la gente participe con voluntad propia, como el caso de 
Cuba, Según (Chaves Salgado, 2015) la animación lectora se comienza a realizar en el Primer Taller Nacional de Promoción de Lectura en 1998, gracias al Sistema de Información para la Educación (SIED). Los autores hablan que son los bibliotecarios los que han profundizado en las actividades para la animación en escuelas, bibliotecas y hogares. Aunque aseguran, que al no ser una frase muy usada no se le había dado la relevancia que se merece, como en la actualidad.

La primera iniciativa en el sistema educativo de incorporar las tecnologías en el Ecuador fue en el año 2002, dotando en las escuelas públicas de equipamientos informáticos, capacitando y entregando PC a los docentes con acceso a internet, según (Peñaherrera, 2011) él no utilizar las TIC en la educación es no vivir en progreso, después de tan ingeniosa iniciativa hubo un gran estancamiento. Con la ausencia de las nuevas tecnologías en el aula las prácticas de enseñanza se ven alteradas, sobre todo, por medios de evoluciones analógicos. La narrativa transmedia es una técnica mediante por la cual se desarrolla una historia mediante videos, sonidos imágenes que puede ser contada en diferentes capítulos y formatos como videos, post, spot y películas en dimensiones $3 \mathrm{~d}$ siendo los estudiantes y docentes participes durante el proceso de realización y expansión.

\section{Las Narrativa Transmedia}

En este sentido, (Tipantuña, 2019) habla de las narrativas transmedia son creaciones que tiene como objetivos crear diferentes formatos mediáticos para emitir el contenido a su vez debe tener lógica para conseguir una experiencia más significativa. Por lo tanto, la comprensión de la lectura es una de las bases herramientas para adquirir conocimientos, pero a su vez es uno de los retos más significativos de las escuelas, razón por la cual se implementará la Narrativas transmedia como estrategias en el aula.

La agregación de la narrativa transmedia a la educación se plantea bajo la hipótesis que es una herramienta adecuada para poner en práctica, entre otros, una buena comprensión, apropiación y remediación de contenidos con un componente motivacional, según (Molas Castells \& Rodríguez Llera, 2017) exhiben que las narrativa transmedia 
implican un proceso de aprendizaje con aportes nuevos con imágenes, sonidos que tienen cambios desde los relatos de inicio es allí donde este medio puede hacer su aporte a la educación, especialmente en la comprensión lectora. Llevando a los estudiantes a crear a partir de lo comprendido del texto inicial o base.

Las narrativas transmedia permiten una mayor inmersión del espectador en la historia, fomentando su implicación y participación, y por tanto, rompiendo con el tradicional rol del espectador pasivo ( Ryan, 2016) dice que el estudiante logra involucrarse, actuar en la creación de una nueva historia, utilizando todos aquellos medios que hacen parte de su diario vivir, como por ejemplo el celular, desde el cual puede crear un video o una radio narración, así está actuando en la creación de sus propios conocimientos.

\section{Comprensión de la Lectura}

La comprensión lectora siempre ha estado ligada al aprendizaje de la lectura, se han convertido en herramientas básicas para una adecuada comunicación y asimilación del mundo. Es así que diferentes investigaciones están enfocadas al desarrollo de estrategias que puedan mejorar y fortalecer estas habilidades. Lo más recomendable para la realización de dichas estrategias es tener ciertas concepciones acerca de la relación existente entre estas habilidades.

Según (Borislova, 2017) afirma que la comprensión de la lectura es un proceso de asimilación de diferentes tipos de ideas, información expresiones siendo una herramienta base para el intercambio de pensamientos entre pares. Es una herramienta base para un desarrollo adecuado en los niños, donde el conocimiento del niño se construye significativamente con la interacción continua entre el leyente, contenido y el argumento, son la clave para formar estudiantes autónomos desarrollando la mente del lector y la correlación entre reflexión y expresión para finalmente obtener la intuición de la lectura. Según (Mora \& Morales, 2016), analizan a la lectura como un asunto de adquirir conocimientos ya sea por interpretar o comprender mediante imágenes. La lectura es un suceso de información guardadas y llevadas mediante algún tipo de lenguaje (visual) al mismo tiempo hace relevancia a una de las habilidades del humano para describir, 
descifrar letras o símbolos de cualquier idioma que este o no inventado por el hombre. La comprensión lectora es una herramienta base para un desarrollo adecuado en los niños, donde el conocimiento del niño se construye significativamente con la interacción, siendo la clave para formar estudiantes autónomos.

Según (Montenegro, Cárdenas, Santrich, \& Sanchez, 2018) expresan que se lee de diferentes medios ya sea por palabras, imágenes o sonidos, distintos lenguajes, estableciendo unos espacios en el que conviven de múltiples modos de lectura, distintas expresiones artísticas que sostienen, con su discurso propio y específico, planos narrativos diferentes. Se puede decir que es una narración corta en diferentes tipos de escenarios donde se combina la creatividad la imaginación creando un espacio de relajación, tranquilidad y paz donde existe el interés en los estudiantes.

\section{Estrategias}

Según (Carbajosa Perez, 2015) define que las estrategias son actividades de animación que auxilian al niño o niña a mejorar la experiencia, lo que forman una estrategia sea excelente, permitiendo llevar acabo mezcla de actividades para motivar a las personas potencializar la lectura en espacios recreativos. Las estrategias son actividades que tienen un fin primordial que despiertan el interés para un aprendizaje integral. Las actividades adecuadas que se aplican en el aula son de gran beneficio en los estudiantes de manera que se fortalezcan los conocimientos, pero es lamentable que hoy en día existan docentes que no estén al tanto de aplicar estrategias, lo cual hace que el estudiante retroceda en sus conocimientos.

Según (Zarina, Núñez, Durango, \& Herazo. , 2017) detallan a las estrategias como un medio que inciden en la motivación siendo un medio que impulsa al aprendizaje por medio del juego logrando así obtener una mejor capacidad intelectual para lograr su objetivo. Es aprovechado como un recurso debido a las relevancias que proporciona en la enseñanza, ya que es la primera mediada esencial para su gozo. El uso de diferentes estrategias relaja, motiva, despierta interés en los alumnos, haciendo énfasis en el juego permite imaginar, crear, recrear y gozar mediante diferentes herramientas, en este 
sentido, pueden considerarse como estrategias a la implementación de las nuevas tecnologías.

La nueva era tecnológica es un bombardeo de información tanto así que las narrativas transmedia hacen uso de redes sociales, televisión, radio, comic, teatro estos son los diferentes lenguajes que los docentes pueden utilizar para una óptima educación teniendo en cuanto que el ser humano nunca es conformista porque siempre busca la manera de interactuar y comunicarse. Se habla inclusive del hombre tecnológico el cual está en constante búsqueda de modificar su entorno para tener más comodidades. En los últimos años esta evolución se ha acelerado en gran medida, el fácil acceso a múltiples y variados contenidos ha llegado a provocar algunas reacciones en contra de estos nuevos medios. La educación no está ajena a estos avances, las aulas cada día están más inmersas en toda esta evolución tecnológica de la cual debe intentar sacar el mejor provecho, por cuanto atacarla se convierte en una guerra perdida.

\section{MÉTODO}

Los datos corresponden a la investigación que se llevó a cabo con los docentes del distrito 03D01 en el año lectivo 2019-2020, compuesto por un universo de 131 docentes de educación básica con un muestreo aleatorio simple de 81 docentes encuestados, el cual parte de un diseño no experimental y transversal, por cuanto los datos recopilados en una sola línea de tiempo (Zhañay-Soliz, Erazo-Álvarez, \& Narváez-Zurita, 2019).

La investigación corresponde a un diseño de tipo descriptiva correlacional mediante análisis de Chi-cuadrado de Pearson con un alcance longitudinal, para la recopilación de inquisición se empleó como técnica la encuesta y como instrumento un cuestionario dirigido a docentes con la escala de valoración Likert la cual mostró 12 preguntas y se realizó de manera digital con Microsoft Forms (Ortega, Erazo, \& Narváez, 2019).

La encuesta se realizó con el propósito de tener información desde el asentamiento de los docentes, con el propósito de conocer si los docentes aplican estrategias nuevas para la comprensión de la lectura. Para el análisis de las deducciones obtenidas se empleó el 
Software SPSS (versión 23), con datos estadísticos de fiabilidad del 0,789 del Alfa de Cronbach. (Vivar-Astudillo, Erazo-Álvarez, \& Narváez-Zurita, 2020).

\section{RESULTADOS}

Se analizaron los principales resultados que partió del problema soez de la comprensión lectora, se presenta esta debilidad o desinterés en muchos estudiantes, motivo por el cual se analizó la relación que existe entre la comprensión de la lectura y la narrativa transmedia como estrategia para el fortalecimiento cognitivo, de la misma manera se constata los docentes no utilizan la narrativa transmedia como estrategia para impartir conocimientos apenas el $1 \%$ lo aplicaron las cuales presentan desconocimiento absoluto estrategias basadas en la narrativa transmedia provocando así el analfabetismo digital, de tal manera esta hipótesis se procedió a analizar el cruce de variables y se obtuvo resultados para la validación o negación.

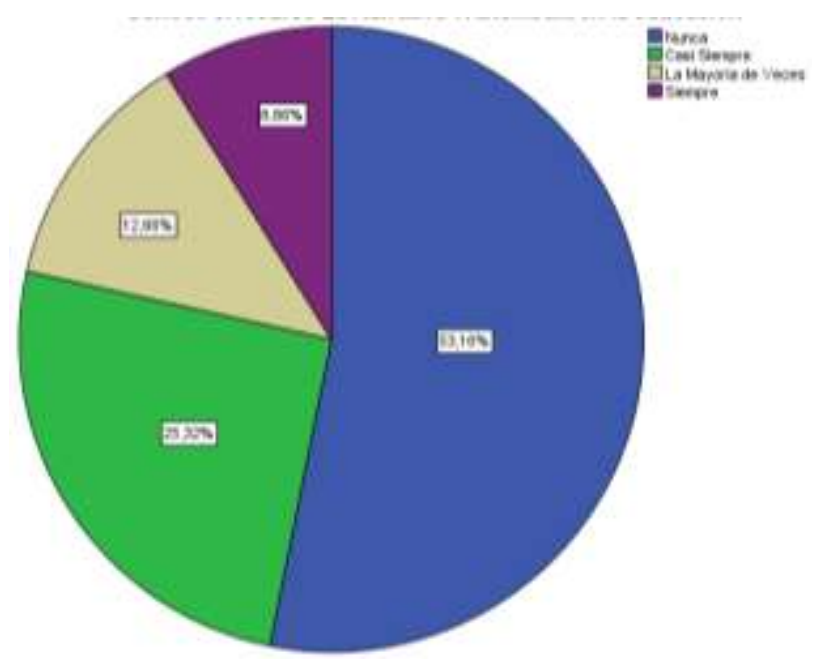

Figura 1. Conoce el recurso Narrativa Transmedia. Fuente: Elaboración propia

Como muestra la figura1 se plantea si los docentes conocen el recurso de la narrativa transmedia para la enseñanza en la educación dando como resultados: con un $8,86 \%$ siempre si conocen acerca del recurso, con un $12,66 \%$ la mayoría de veces o algo conocen del recurso, con un $25,32 \%$ casi siempre o casi nada conocen del recurso y con 
un 53,16\% nunca no conocen nada acerca de la Narrativa Transmedia, dando como problema la inexperiencia y la inexactitud de formación en los docentes para impartir clases por medio de la tecnología con este recurso innovador para la enseñanza en la educación.

\section{Tabla 1}

Tabla cruzada Dificultad para comprender*Frecuencia de leer textos académicos. Resultado de Chi cuadrado

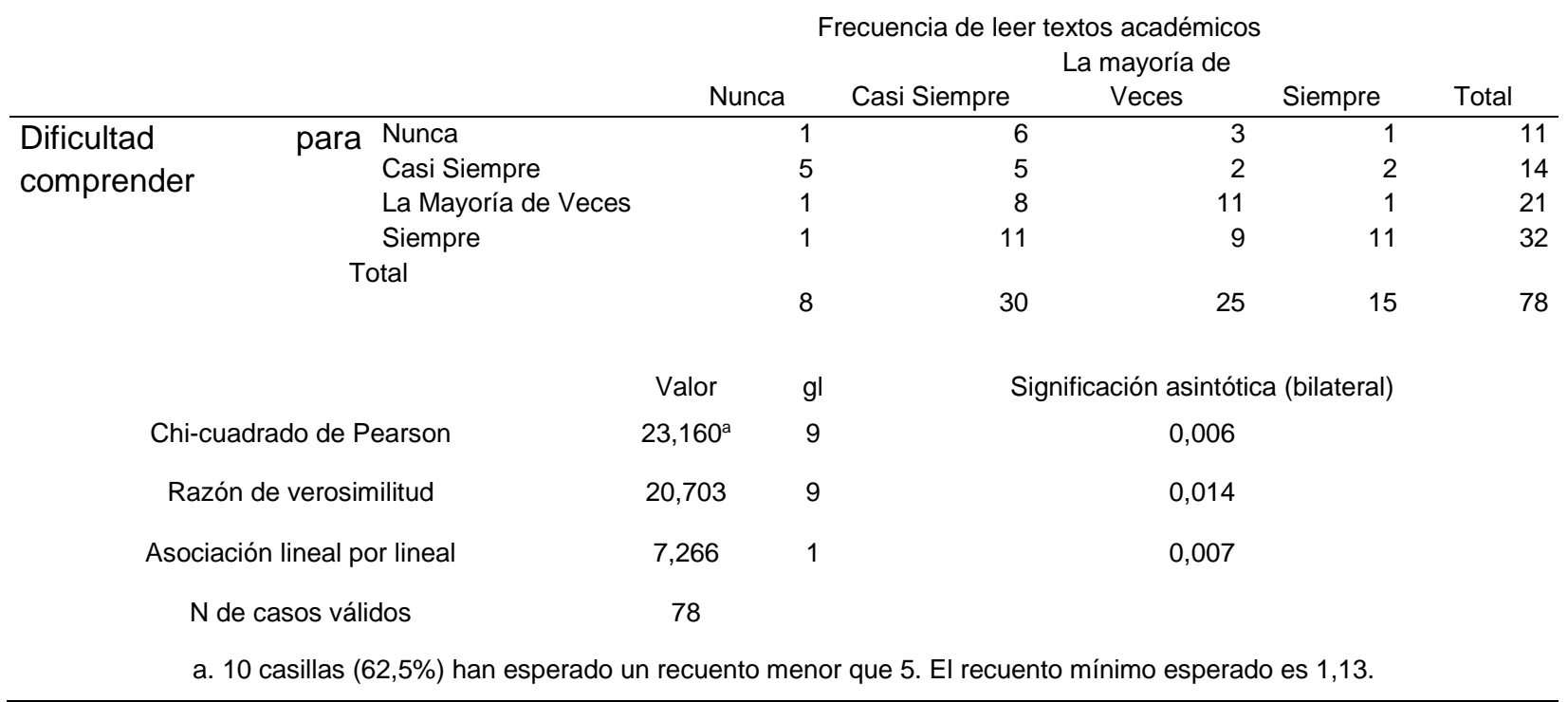

\section{Fuente: Elaboración propia}

Mediante la tabla 1 se dio por la hipótesis afirmativa $\mathrm{H} 1$, demostrando que existe dos variables asociadas y relacionadas entre sí, afirmando con el Chi cuadrado se resolvió que existe dificultad de comprensión lectora por falta de estrategias, razón por la cual leen por obligación y por cumplir tareas de manera forzada ocasionando así el desinterés por la lectura en estudiantes y docentes, explicando con un $32 \%$ que siempre tienen dificultad por comprender, con un $21 \%$ indicaron la mayoría de veces, con un $14 \%$ casi siempre presentan dificultad y con un $11 \%$ nunca presentan dificultad para comprender textos académicos, lo que conlleva a un gran problema por la falta de estrategias basadas 
Revista Arbitrada Interdisciplinaria KOINONIA

Año 2020. Vol V. ํ⒈ Especial Educación

Hecho el depósito de Ley: FA2016000010

ISSN: 2542-3088

FUNDACIÓN KOINONIA (F.K). Santa Ana de Coro. Venezuela.

Angélica María Sánchez Morocho; Darwin Gabriel García-Herrera; Nancy Marcela Cárdenas-Cordero; Juan Carlos Erazo-Álvarez

en las herramientas digitales como lo es la narrativa transmedia que sirve de gran ayuda para mejorar el fomento de la lectura.

\section{Tabla 2}

Tabla cruzada Uso de la Narrativa Transmedia para enseñar*El implementar el recurso Narrativa Transmedia es motivador en la educación. Resultado de Chi cuadrado

\begin{tabular}{|c|c|c|c|c|c|c|}
\hline & & \multicolumn{4}{|c|}{$\begin{array}{l}\text { El implementar el recurso Narrativa Transmedia es motivador en } \\
\text { la educación }\end{array}$} & \multirow[b]{2}{*}{ Total } \\
\hline & & Nunca & Casi Siempre & $\begin{array}{c}\text { La Mayoría de } \\
\text { Veces }\end{array}$ & Siempre & \\
\hline \multirow{4}{*}{$\begin{array}{l}\text { Uso de la Narrativa } \\
\text { Transmedia para enseñar }\end{array}$} & Nunca & 3 & 16 & 8 & 8 & 35 \\
\hline & Casi Siempre & 0 & 5 & 7 & 12 & 24 \\
\hline & La Mayoría de Veces & 0 & 1 & 5 & 10 & 16 \\
\hline & Siempre & 0 & 0 & 1 & 0 & 1 \\
\hline \multicolumn{2}{|c|}{ Total } & & 22 & 21 & 30 & 76 \\
\hline \multirow{2}{*}{\multicolumn{2}{|c|}{ Chi-cuadrado de Pearson }} & Valor & $g \mid$ & \multicolumn{2}{|c|}{ Significación asintótica (bilateral) } & \\
\hline & & $18,542^{\mathrm{a}}$ & 9 & \multicolumn{2}{|c|}{,029 } & \\
\hline \multicolumn{2}{|c|}{ Razón de verosimilitud } & 20,566 & 9 & \multicolumn{2}{|c|}{, 015} & \\
\hline \multicolumn{2}{|c|}{ Asociación lineal por lineal } & 12,594 & 1 & \multicolumn{2}{|c|}{, 000} & \\
\hline \multicolumn{2}{|c|}{$\mathrm{N}$ de casos válidos } & 76 & & & & \\
\hline
\end{tabular}

Fuente: Elaboración propia.

Se observa en la tabla 2 el resultado mediante la hipótesis afirmativa $\mathrm{H} 1$; el uso de la narrativa transmedia para enseñar es una de las estrategias para la educación, el implementar este recurso considerable llegando a los niños de una forma nueva e innovadora de esta forma tener un óptimo aprendizaje. lo cual demostró que los docentes no utilizan estas herramientas digitales y algunos de ellos hasta desconocen de su existencia, teniendo en cuanta que es de optimo beneficio en la educación de los estudiantes y más aún en la enseñanza como lo es la lectura, como reflejo en tabla con un $1 \%$ siempre implementan, con $16 \%$ la mayoría de veces, con $24 \%$ casi siempre y con un $35 \%$ nunca implementan estrategias basadas en narrativa transmedia. 
Confirmando así que los docentes deben implementar el uso de estas herramientas por medio de aplicaciones ya sea mediante la utilización del computador, Tablet o móvil en cual sea de su agrado logrando mejorar la comprensión lectora por medio de aplicaciones que generan el interés por la lectura siendo un hábito de optima importancia para la educación de hoy en día. El análisis del Chi cuadrado confirma que es h1; es afirmativa ya que se encuentran asociadas o tienen relación, resolviendo el enseñar mediante las estrategias basadas en la narrativa transmedia es esencial y fomentador dejando en si el interés por la lectura.

Se analiza la investigación que existe un analfabetismo transmedia desde el docente facilitador de conocimientos, lo cual implica un problema para el aprendizaje de los estudiantes, el profesor es el principal actor promoviendo enseñanzas de calidad lo cual permite focalizar en las herramientas digitales, recursos innovadores aplicaciones, cabe recalcar que las estrategias fundadas en las narrativas transmedia pueden ser crecidamente enérgicas con relación a la lectura dándose así una mejora de relación entre el docente y el estudiante dejando en el pasado lo tradicional donde los niños no sienten ningún interés por leer los textos (Chacha-Supe \& Rosero-Morales, 2020).

Según (Acosta, 2018) manifiesta que las actividades que realizan los docentes son tradicionalistas y monótonas impidiendo a sus estudiantes al avance de sus conocimientos. Sin embargo, en la actualidad se debe buscar las posibilidades de comunicación el proponer y capacitar para que comprendan la importancia de implementar las narrativas transmedia de manera estratégica para proponer a los estudiantes a la creación de la transmedia por cuanto es factible en todas las materias logrando la creatividad y el entusiasmo por la educación.

Uno de los inconvenientes que se vive en la educación es la comprensión de la lectura, si bien se dice que es la base herramienta de los posteriores aprendizajes (Borregales, 2020), la visión leedora es el beneficio de un juicio dado por el lector que produce información del que brinda el texto leído, el problema se da cuando el lector no muestra interés por leer (Dovale, 2018), esto se debo a la falta de mecanismos y estrategias desde luego que lo hacen por cumplir con sus obligaciones diarias y el que me 
importancia si no son de su agrado las investigaciones, teniendo en cuanta que existen diversos recursos para que el estudiante desarrolle el hábito lector a medida vaya congeniando con la comprensión de textos.

Según (Gomez, 2011) habla sobre la lectura no es únicamente la reproducción de sonidos y fonemas al contrario es entender el mensaje el cual nos tratan de transmitir. La comprensión lectora es definida como la destreza para interpretar y producir sonidos, fonemas intérprete ya sea por gráficos, historias, videos y folletos y pueda dar sus juicios de valor, la lectura juega el papel más importante en el aprendizaje favoreciendo su desarrollo integro.

Por lo dicho es precisamente necesario el implementar como estrategias basadas en la narrativa transmedia por sus indudables ventajas que trae en la comprensión de la lectura ya que al mismo tiempo atrae al estudiante con sus abrumarles audios, videos, imágenes 3D de manera que se familiarice con los entornos virtuales y de la misma manera ser un factor motivacional, así se deduce que las narrativas transmedia permiten realizar aprendizajes virtuales.

Según (Amador Baquiro, 2018) habla sobre las narrativas trasmedia como un recurso innovador para la eduacion, de tal manera que se expande en diversos sistemas como audiovisuales, interactivas, videojuegos, comic en diferentes medios por ejemplo el cine la televicion o el teatro, de esta manera surge o nace los realtos dramas - tramas, personajes la cual combinan con historias ficticias o de hechos reales despertando en si la imaginacion, la creatividad para crear en el lector interes por ir descubriendo cada ves mas. Para finiquitar, se afina que las narrativas transmedia dan recuento de programas atractivos. Infaliblemente, es un asunto expansivo en asuntos de fijación que brota como tendencia especializada y pedagógica. La aplicación de modernas experiencias en los usuarios, quienes como comunidades del saber. 


\section{PROPUESTA}

En la práctica pedagógica el docente debe establecer contenidos interesantes y que forjen complicación para certificar la utilidad de los educandos y que subsiguientemente, socorrerán a la locomoción de estos textos narrativos. Esta cultura digital se basa en la ciencia digital utilizando los recursos innovadores, el docente ordinariamente participa como presentador logrando la curiosidad del destinatario aptos para reconocer el mensaje tal como se enseñan, al mismo tiempo los profesionales en la educación deben actualizarse y poner en evidencia el virtual apoyo del entorno digital, los procesos educativos deben ser flexibles y abiertos favoreciendo la construcción y desarrollo de los contenidos escolares.

La propuesta que se da es el implementar los recursos tecnológicos e innovadores a través de diferentes aplicaciones que hoy en día se utiliza para tener éxito en el aprendizaje, se proyecta instruir a educativos para que perciban la razón de la narrativa transmedia y la puedan emplear. El modelo de implementación de estrategias basadas en la narrativa transmedia se efectuó con 4 aspectos claramente definidos: describir, explorar, diseñar e implementar con el propósito de optimar la comprensión lectora.

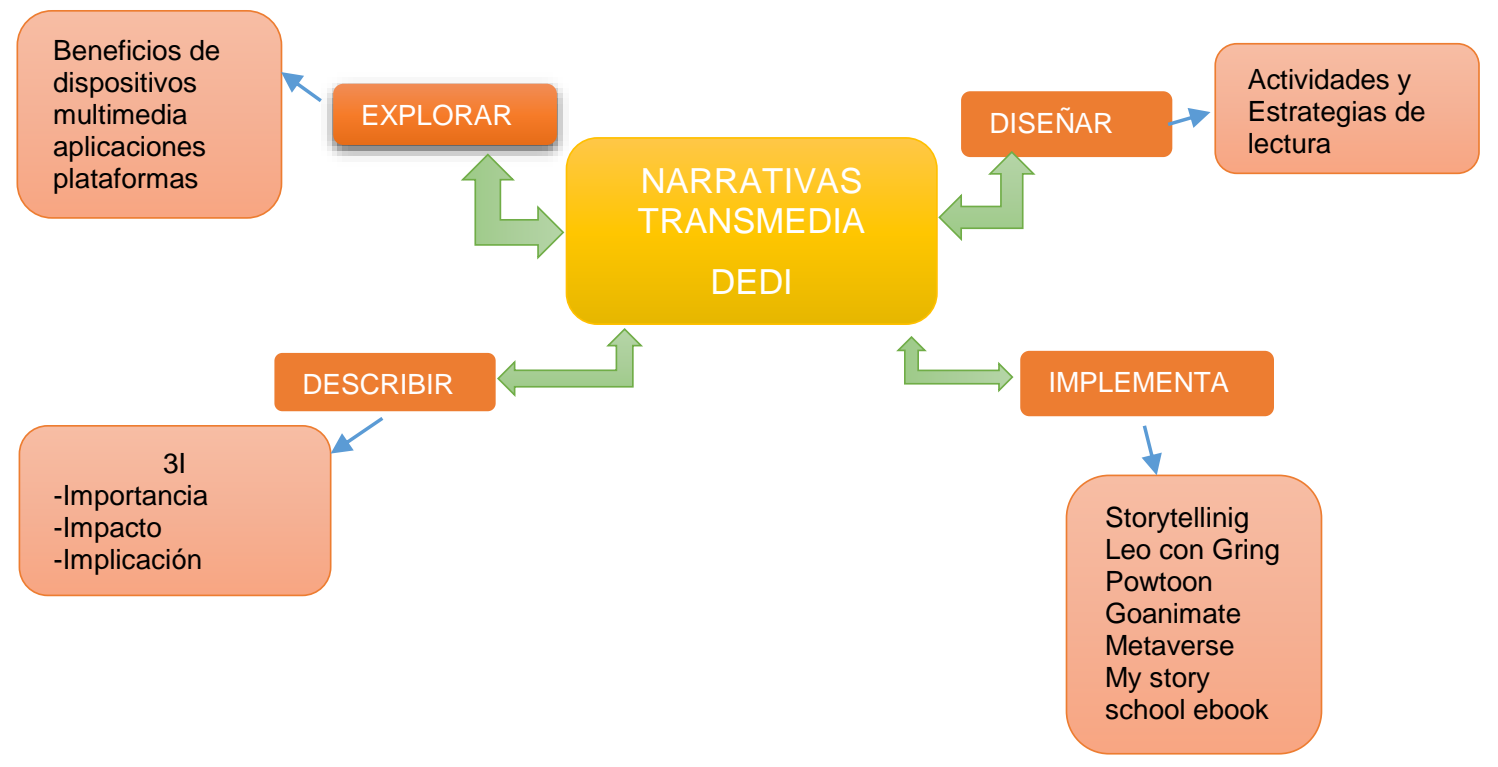

Figura 2. Metodología Empleada. Fuente: Elaboración propia 
Describir. La importancia de utilizar las narrativas transmedia en la educación, tiene una potencialidad al momento de enseñar contenidos curriculares lo cual se trata de desarrollar una experiencia de exploración y elaborar formatos de comunicación para la lectura en el transcurso de educar. Así mismo la importancia de la inercia de la narrativa transmedia en el alumnado tuvo cambios en el modelo de formación, tanto en el educador como en el educando instruyéndose de la mejor forma así mismo vinculando las destrezas emocionales, cognitivas y sociales, logrando en si mejorar la comprensión lectora.

Explorar. Las ventajas académicas al utilizar la narrativa transmedia en la educación es más fructuoso, ayudan a enriquecer el contenido del trabajo que se desenvuelve al igual que los estudiantes logran participar en sus mismos conocimientos, rebuscando adicional información gracias a los dispositivos ya se computador, tableta o móvil, de manera divertida recolectando, creando y almacenando datos con información real, con la ayuda de las plataformas por otra parte la multimedia facilita las exposiciones de trabajos, la exportación continua de información, pensamientos, ideas o reflexiones gracias a estas herramientas mejoran los tiempos, enfatizando organizar trabajos y tareas, por otra parte las diferentes aplicaciones que se utiliza para crear y leer son necesarias y se debe implementar en la educación.

Diseñar. La narrativa transmedia incluye dinamismos que apoya en la alfabetización digital que sea clara y sencilla es fundamental para enseñar, puedes determinar que herramientas digitales utilizaras ya sea por videos, fotos, infografías, entre otros, el utilizar las redes sociales deben pueden ser las más adecuadas para la comprensión lectora, el disponer de e Books adaptativos los libros electrónicos a la educación es una excelente oportunidad para realizar actualización de la información en todo momento, interactuar con los estudiantes, ofrecer un material que considere las necesidades de cada joven, entre otras ventajas que es imposible obtener a través del material impreso del cual motive al estudiante, el promover el aprendizaje grupal para interactuar e intercambiar constantes conocimientos para lograr un óptimo desempeño escolar. 
Implementar. Un plan estratégico para la enseñanza son las competencias transmedia y los saberes escolares, el cual podemos utilizar para el desarrollo de la lectura que va desde la creación de un sitio web, animaciones y videos, gestión de redes sociales, realización de piezas gráficas y rediseño de un videojuego, en cada caso se recuperaron diferentes competencias transmedia como: Creación de un sitio web: como Powtoon, My story school ebook maker, las animaciones y videos audiovisuales; usar recursos para reproducir y publicar; actuar; buscar, seleccionar y descargar como Goanimate.

Realización de piezas gráficas: crear y modificar producciones fotográficas y usar herramientas fotográficas y de edición, creación de un videojuego Metaverse, scratch, Sploder y leo con Gring son aplicaciones en las cuales nos brindan para desarrollar el coeficiente intelectual de manera que cause en el lector interés y curiosidad y por ultimo tenemos a Storytelling es una práctica narrativa que consiste en crear historias imaginarias realizando en varios medios, agregando su diario vivir, Cada recurso digital muestra la historia diferente en diferentes espacios, tiempos, colores, personajes y diferentes estados de ánimo.

\section{CONCLUSIONES}

Podemos concluir que la comprensión lectora interviene elocuentemente en el beneficio escolar, por lo que se puede afirmar que al utilizar las estrategias basadas en la narrativa transmedia influye mayormente en el rendimiento escolar, puesto así se constata que si se tiene una enseñanza tradicional causa dificultad en el contexto educativo, se considera que el proceso de mejoramiento de la eficacia formativa es la implementación de estrategias aprovechadas a la educación, que manifiesta a un proceso de formación empleando herramientas, aspecto que limita a mejoras.

Se debe incorporar en los contextos educativos herramientas que compensen la educación significativa ,aludiendo el impulsar el uso y manejo de las narrativas digitales, planteado desde el manejo de un sistema didáctico, que permita estimular los procesos de enseñanza y aprendizaje, integrando lenguajes visuales, sonoros y sensoriales, para de esta forma garantizar procesos de transferencia del conocimiento, de manera 
dinámica, activa y que active el contenido emocional en los resultados del aprendizaje, la narrativa transmedia está teniendo una importante apertura en la vinculación de experiencias educativas mediadas por el uso de las nuevas tecnologías, deberán manejar el sistema comprensible para instruir a los educandos a relacionar, percibir y fundar la idea de manera afanosa e Inspirar el manejo de las disposiciones epistemológicas de modo integral y sistémica.

Las narrativas transmedia propician un rol activo y protagónico por parte de los alumnos, utilizando la creatividad como motor de cualquier producción realizada, explorando sus propias inquietudes, gustos e intereses para expandir un universo.

Las narrativas digitales se describen dentro de una misma dirección que de alguna forma se ha trasladado en educación con un modelo educativo transitivo, en donde los docentes son expertos. Finalmente, podemos decir que la clave para trabajar en la comprensión lectora es la implementación de las estrategias basadas en las narrativas transmedia favoreciendo los roles que permiten explorar y explotar las habilidades/competencias comunicacionales y digitales de los alumnos.

\section{FINANCIAMIENTO}

No monetario.

\section{AGRADECIMIENTO}

A la Universidad Católica de Cuenca, por impulsar el desarrollo del proceso investigativo.

\section{REFERENCIAS CONSULTADAS}

Acosta, A. H. (2018). Innovación, tecnologías y educación: las narrativas digitales como estrategias didacticas[Innovation, technologies and education: digital narratives as $\begin{array}{llll}\text { didactic strategies]. } & \text { Killkana, 2(2), }\end{array}$ doi:https://doi.org/10.26871/killkana_social.v2i2.295 
Amador Baquiro, J. C. (2018). Interactive Education through Transmedia Narratives: Possibilities at School. [Educación interactiva a través de narrativas transmedia: posibilidades en la escuela]. Revista Internacional de Investigación en Educación., 10(21), 71-94. doi:doi: 10.11144/Javeriana.m10-21.eint

Borislova, N. (2017). Desarrollo de la creatividad en la primaria a partir del cuento musical[Development of creativity in primary school based on the musical story]. RIDE Revista Iberoamericana para la Investigación y el Desarrollo Educativo, 7(14), 6-9. Obtenido de https://n9.cl/zwa90

Borregales, L. (2020). Génesis y evolución socio-histórica de la macro categoría cultura escrita. [Genesis and socio-historical evolution of the macro category written $\begin{array}{llll}\text { culture]. } & \text { EPISTEME } & \text { KOINONIA, } & 3(5),\end{array}$ http://dx.doi.org/10.35381/e.k.v3i5.529

Carbajosa Perez, M. (2015). El cuento: nuevas formas de creación, difusión y lectura [The story: new forms of creation, dissemination and reading]. Opcion, 31(5), 200. Obtenido de https://n9.cl/5w29

Chaves Salgado, L. (2015). Estrategias para el fomento a la lectura: ideas y recomendaciones para la ejecución de talleres[Strategies for promoting reading: ideas and recommendations for running workshops]. Revista e-Ciencias de la Información,, 5(2), 1-15. Obtenido de https://n9.cl/k9sj

Chacha-Supe, M., \& Rosero-Morales, E. (2020). Procesos iniciales de enseñanza aprendizaje de la lectoescritura en los estudiantes del nivel de preparatoria. [Initial teaching-learning processes of literacy in high school students]. Revista Arbitrada Interdisciplinaria Koinonía, 5(9), 311-336. http://dx.doi.org/10.35381/r.k.v5i9.650

Dovale, Y. (2018). Las habilidades resuntivas de ensayos académicos expositivos en estudiantes de la Universidad Nacional Experimental Francisco de Miranda. [The residual skills of expository academic essays in students of the Francisco de Miranda National Experimental University]. EPISTEME KOINONIA, 1(1), 18-34. http://dx.doi.org/10.35381/e.k.v1i1.488

Domínguez Correa, B. (2016). Análisis del fenómeno BookTube en España[Analysis of the BookTube phenomenon in Spain]. La prioridad de la Lectura, 23-30. Obtenido de https://n9.cl/kfgi

Gomez, P. J. (2011). Comprension lectora y rendimiento escolar : ruta para mejorar. [Reading comprehension and school performance: a route to improvement]. Revista de Investigación en Comunicación y Desarrollo., 2(2), 27-36. Obtenido de https://n9.cl/wwdb 
Instituto-Nacional-Censos. (2019). Hábitos de Lectura en Ecuador[Reading habits in Ecuador]. Instituto nacional de Estadistica y Censos. Obtenido de https://n9.cl/5sok

López López, M. L., \& Martínez Viteri, M. (2019). Universidad central del Ecuador. Booktubers y animación a la lectura. Análisis de contenido de los videos de Booktubers Ecuatorianos[Booktubers and reading animation. Content analysis of Ecuadorian Booktubers videos], 149. Obtenido de https://n9.cl/yr7ec

Ministerio-Educación. (2014). Currículo de educación. MInisterio-Educación. Obtenido de https://n9.cl/u00c2

Molas Castells, N., \& Rodríguez Llera, J. L. (2017). La narrativa transmedia: la Carta Ancestral en educación secundaria[The transmedia narrative: the Ancestral Letter in secondary education]. Razón y Palabra,, 21(98), 221-233. Obtenido de https://n9.cl/nr0g

Montenegro, F., Cárdenas, M., Santrich, R., \& Sanchez. (2018). Factores asociados a la comprensión lectora en estudiante de noveno grado de Barranquilla[Factors associated with reading comprehension in a ninth grade student from Barranquilla]. Revista Psicogente, 19(36), 296-310. Obtenido de https://n9.cl/y9yd

Mora, Z., \& Morales, P. (2016). Fortalecimiento en los Procesos Lecto-Escritos en Primera Infancia a través de Blended-Learning[Strengthening of Reading and Writing Processes in Early Childhood through Blended-Learning]. Revista Iberoamericana sobre Calidad, Eficacia y Cambio en Educación, 14(1), 117-135. Obtenido de https://n9.cl/p33k

Ortega, O. F., Erazo, J. C., \& Narváez, C. I. (2019). Evaluación técnica y financiera de proyectos productivos aplicando lógica difusa [Technical and financial evaluation of productive projects applying fuzzy logic] Recuperado de: https://n9.cl/2r74. Cienciamatria, 298-327. doi:https://doi.org/10.35381/cm.v5i1.268

Peñaherrera, M. (2011). Evaluación de un programa de fortalecimiento del aprendizaje basado en el uso de las TIC en el contexto ecuatoriano[Evaluation of a program to strengthen learning based on the use of ICT in the Ecuadorian context]. Revista Iberoamericana de Evaluación Educativa, 4(2), 72-91. Obtenido de https://n9.cl/7c8j

Raúl Fraguela, V., Pose Porto, H., \& Lara, V. (2016). Tiempos escolares y lectura[School times and reading]. Ocnos: Revista de Estudios sobre Lectura, 15(2), 67-76. Obtenido de https://n9.cl/4fnm

Rugerio, J. P., \& Guevara , Y. (2015). Alfabetización inicial y su desarrollo desde la educación infantil [Initial literacy and its development from early childhood education]. Revisión del concepto e investigaciones aplicadas. Ocnos, 13, 25-42. Obtenido de https://n9.cl/ayabd 
Ryan, M.-L. (2016). Narratologia transmèdia i transmedia storytelling. Narratologia transmèdia i narrativa transmedia]. Artnodes, 18, 2-5. Obtenido de https://n9.cl/p2os

Tipantuña, J. (2019). Uso de narrativas digitales como recurso didáctico para el aprendizaje adulto: propuesta de diseño para su integración en el aprendizaje permanente[Use of digital narratives as a didactic resource for adult learning: design proposal for its integration..]. Digital Publisher, 4(2), 32-33. doi:DOI: https://doi.org/10.33386/593dp.2019.4.114

Vivar-Astudillo, A. Y., Erazo-Álvarez, J. C., \& Narváez-Zurita, C. I. (2020). La cadena de valor como herramienta generadora de ventajas competitivas para la Industria Acuícola [The value chain as a tool generating competitive advantages for the Aquaculture Industry]. Revista Arbitrada Interdisciplinaria Koinonía, 4-33. doi:http://dx.doi.org/10.35381/r.k.v6i10.686

Zapata Villa, Y. C. (2019). La narrativa Transmedia : es el fortalecimiento de la comprensión de la lectura[The Transmedia narrative: is the strengthening of reading comprehension]. Universidad Pedagógica Nacional Educa Educadores, 76-. Obtenido de https://n9.cl/a18p

Zarina, R., Núñez, R., Durango, M., \& Herazo. , R. (2017). Niveles de comprensión lectora en los estudiantes de la Corporación Universitaria[Reading comprehension levels in the students of the University Corporation]. Revista Virtual Universidad Católica del Norte., 51, 156-174. Obtenido de https://n9.cl/07s1

Zhañay-Soliz, O. A., Erazo-Álvarez, J. C., \& Narváez-Zurita, C. I. (2019). Modelo de Auditoria de Sistemas de Información para las Cooperativas de ahorro y crédito del segmento 1, 2, y 3, de la ciudad de Cuenca [Information Systems Audit Model for Savings and Credit Cooperatives of Segment 1, 2, and 3] Recu: https://n9.cl/ah7bo. Cienciamatria, 361-393. doi:https://doi.org/10.35381/cm.v5i1.271

2020 por los autores. Este artículo es de acceso abierto y distribuido según los términos y condiciones de la licencia Creative Commons Atribución-NoComercial-Compartirlgual 4.0 Internacional (CC BY-NC-SA 4.0) (https://creativecommons.org/licenses/by-nc-sa/4.0/). 